\title{
A New Probe into the Talent-cultivating Mode of "Development of Morality and Skills" in Postgraduates Majoring in Physical Education
}

\author{
Lizhong Wen \\ College of Sports Science \\ Jishou University \\ Jishou.416000.China \\ Wenlizhong1107@163.com
}

\author{
Yufeng Chen \\ College of Sports Science \\ Jishou University \\ Jishou.416000.China \\ 278670622@qq.com
}

\begin{abstract}
The rapid development of China's sports industry in the new era has placed higher demands on high-level sports talents, in order to develop to adapt to the state of modern science and technology development and social progress of high level sports talents demand, the need to develop comprehensive development and innovation and development of postgraduate sports disciplines, more optimal cultivation mode of postgraduate sports discipline. The master of physical education should cultivate moral education while improving the professional ability, so that the high level of sports talents can have both skills and skills. This paper analyzes the problems found in the current master training of sports disciplines, for example, The students' ability to independently conduct scientific research is not strong, the training process lacks competition and incentive mechanisms, and the selection process is not targeted. Therefore, it puts forward the practice of the "virtual stylistic" talent training mode in the training of postgraduates for sports disciplines, so as to provide valuable reference for the cultivation of master postgraduate in sports disciplines.
\end{abstract}

Keywords-Sports discipline; Master's degree; Length of German operation; Cultivation of talents

\section{INTRODUCTION}

In the training of postgraduate in sports, the University of Michigan, Ohio State University, and Indiana University all have the "cultivation as the center" and the "quality standard" as the main training concept for postgraduate and that explain that the cultivation of American talents emphasizes the correctness of the purpose of human beings' physical and mental development. Sports learning graduate student cultivation of quality education in China are still not enough, the main problems in graduate education, the graduate student of the current political orientation problem of lack of deep thinking, their ability to accept new ideas, but it loads thin in terms of the combination of professional knowledge and practice. The mode of teaching is still subject to the current book knowledge, which lacks the cultivation of the application and ability of the postgraduate knowledge. The ability of postgraduate to solve practical problems is not strong, they lack the connection with the actual situation, and their collective consciousness and cooperation spirit are poor. They often struggle alone to achieve their personal goals. The

Fund Project: Research project of the 2017 degree and graduate education reform of Jishou University (JG2017B06) psychological quality of some postgraduate has some deviation, the quality of will and the ability to withstand setbacks are weak.[1] With the increasing enrollment of postgraduate, it has become an accepted fact that the quality of postgraduate in China has decreased. Therefore, the construction of a comprehensive quality platform model for the basic quality education for postgraduate in sports, a full-scale participation model for professional quality education, and a cultural integration model for innovative quality education are the basis for the training of "quality-oriented" education for postgraduate in sports, and all of that should be given full attention.

\section{TAlented Personnel Training Model of "DEVELOPMENT OF MORALITY AND SKILLS"}

We are in line with the overall goal of postgraduate as a whole, which is that graduate education should cultivate highlevel research or applied talents for national and local economic development, social progress, and discipline development. Generally speaking, social development requires talents who are really engaged in original research for some basic disciplines, but the demand will not be too large and the talent needs and supply follow the first principle of quality and level. What is needed for some applied disciplines is a highlevel talented person with corresponding specialized skills. Social demands are quite large about those people, so the huge demand for such talents is becoming the primary principle. Therefore, "master level talents concentrate resources on the development of high tech professionals, senior management personnel and advanced applied talents that are urgently needed by the society[2].

China's sports degree and postgraduate education and highlevel personnel training have made remarkable achievements, and made important contributions to the development of China's sports undertakings. However, the contradiction between the monotonous training model for high-level sports personnel and the limited training scale has become increasingly prominent. , it is necessary to introduce the training mode of professional degrees and set the professional degree of sports masters while retaining the existing research model of high-level personnel training for sports disciplines. At present, sports are a first-degree subject in China under the category of education. Among the two subordinates, the other 3 
majors are awarded the degree of education except that the major of sports human science can be granted to both science and education. Postgraduate sports disciplines, in the entrance examination, training objectives, curriculum setting, teaching arrangement and paper are in accordance with the secondary discipline with the academic, research personnel training mode. According to the characteristics of sports discipline and the demand of high-level sports talents, the mode and key point of training postgraduates of physical education should be practical personnel. Therefore, it is necessary to adjust the structure of sports disciplines and the cultivation of high-level personnel, and shift the focus of post-graduate education in sports subjects from the cultivation of knowledge-based and academic-type talents to the transformation of highly talented personnel with common development of morality and skills[3].

Most of the postgraduates majoring in sports are engaged in skills teaching and research and the professional skills of the system are very necessary for the future work. The main goal of postgraduate training is to develop the overall development of morality, intelligence and physical. It is able to carry out teaching, training, scientific research and management in the field of physical education and training and has a more solid professional knowledge and research ability are to meet the requirements of social development. With the enrollment expansion of undergraduate education, postgraduate education in China has also greatly expanded the enrollment scale, and the postgraduate of physical education are expanding enrollment to meet the needs of the society. Finally, how to improve the professional skills of postgraduates is the main task that must be solved in the training of master of physical education.

\section{Problems existing In the training of Postgraduates} IN SPORTS DISCIPLINE

\section{A. Postgraduate are not strong enough to engage in scientific research independently.}

The quality of master's degree thesis should be a concentrated expression of a series of abilities of postgraduates with independent scientific research work, for example, review search documents, select thesis titles, formulate scientific research plans, submit open-ended reports, conduct scientific research, acquire and process data, images, etc. , and summarize, analyze, compare, and synthesize the data. From the process of thinking in the table and inside, through theoretical proof, to draw innovative conclusions, the paper is revised and finalized, reported, communicated or collected in various academic conferences at home and abroad, and published in various academic journals. Sometimes it is also reflected in the timely development of scientific research results into social and economic benefits[4].

\section{B. The lack of competition and incentive mechanism in Postgraduate training}

On the one hand, there is a lack of elimination mechanism in the process of postgraduate study, and students' selfconsciousness, initiative and enthusiasm, Students can finish their studies with hard work, and the difference between high scores and low marks is not big, which is actually the embodiment of the 'the communal-dining system. " On the other hand, the personnel system is not perfect, lack of incentives for tutors, and lack of evaluation of tutors. That makes it impossible for a tutor to lose the qualification of a postgraduate student, regardless of the quality of postgraduate, whether he has scientific research projects or high level research results. To sum up, it is difficult to mobilize the enthusiasm of all aspects. With the rapid development of postgraduate education in our country, the enrollment scale of postgraduate is continuously expanding and they are come from different disciplines, and their knowledge structure is quite different such as some postgraduate have strong practical abilities, but their theoretical abilities are weak.

\section{The selection process of master postgraduate is not scientific; it is difficult to select students with innovative ability and development potential}

The selection of postgraduates in China places too much emphasis on the test scores, which runs counter to the purpose of cultivating postgraduate. Therefore, the selection of graduate with good personal qualities, hobbies, potentials, pursuits, personality characteristics, and quick thinking is an important aspect that determines the development of a master's degree. According to the basic principles of behavioral science, human needs are the initiators that drive people to engage in work and creative activities. So master's graduate education must be based on the needs of postgraduate. Only by accurately understanding and grasping the needs of postgraduate, and then satisfying and developing the needs of master postgraduate, so that we can achieve the goal of inspiring postgraduate education.

\section{The Practice of Talent Cultivation Mode of "DEVELOPMENT OF MORALITY AND SKILLS" IN THE TRAINING of Postgraduates Majoring in Physical EduCATION}

\section{A. Need to improve the ability of master postgraduate to find problems and solve problems}

Finding the problem is the logical starting point for scientific research, and it is also the focus of cultivating postgraduate research ability. And solving problems is a process of comprehensively using their own knowledge and ability to find the answers to problems and improving scientific research ability, and it is also one of the logical end points for cultivating postgraduates' scientific research capabilities. There are many deficiencies in postgraduate in this country, the concrete expression is :(1) the problem consciousness is not strong, not good at discovering the problem; (2) it is not good at articulating and defining problems clearly; (3) it is not good at seeking suitable solutions according to problems and realistic conditions;(4) it is not good at implementing solutions to problems; (5) it is not good at evaluating or verifying the correctness of the solution[5].

\section{B. Need to master interdisciplinary knowledge}

Due to the development of modern science and technology and the emergence of multi-disciplinary and interdisciplinary disciplines, solving problems can be solved not only by relying on one or two knowledge items, but also by relying on multi- 
disciplinary knowledge. Therefore, mastering multidisciplinary and interdisciplinary knowledge is of great importance for expanding the knowledge of postgraduate and enhancing the use of knowledge. It is also important to master strict methodologies. The method is the key to solving the problem. China's sports graduate methodological methodology is seriously inadequate, and the methodology is not very practical. It is not conducive to the graduate student applying a reasonable, effective, and reliable method to solve practical problems in the sports field, and it is also not conducive to postgraduate to solve practical problems when innovation in scientific methods. To sum up, the strengthening of graduate frontier professional knowledge learning, interdisciplinary knowledge learning and methodological knowledge learning is the guarantee for the realization of the "knowledge-based" talent cultivation concept of sports postgraduate. In the graduate master training process, the tutor is not only the imparter of knowledge, but also the leader who promotes the overall quality and ability improvement of the master graduate student.

By the way, the academic level, management level and guiding ability of the tutor are very important to the growth of the master graduate student. It means that it is necessary to strengthen the rights and responsibilities of the tutor, clarify the responsibilities of tutors, play a role as a tutor, and closely integrate talent cultivation with scientific research, so as to create incentives for stimulating the graduates' enthusiasm for innovation and innovative practice. It is necessary to further clarify the responsibilities, rights, and benefits of mentors in the cultivation of postgraduate, and strengthen the selection, funding, and assessment of mentors for mentors and strengthen the mentors' responsibilities. At the same time, through the role of the steering group, the relationship among the tutor, the steering group, and the master graduate student is redefined and confirmed, and the funding for the master graduate student is combined with the actual performance to form a favorable incentive for stimulating the graduates' enthusiasm for innovation and innovative practice and funding[6].

\section{Strengthen the campus academic environment}

The impact of the environment on people is imperceptible. It is necessary to strengthen the academic environment on campus and widely carry out academic exchange activities. We must focus on cultivating the scientific spirit, humanistic quality, academic ethics, innovative spirit, and team awareness of postgraduate, and organize academic forums and scientific and technological culture festivals and academic exchanges at school and abroad. We can hold some activities such as Sports discipline master graduate academic activity contest, postgraduate academic forum, academic report conference, academic salon. All of these activities can promote academic research and cultural exchanges among postgraduate, invigorate the academic atmosphere, stimulate enthusiasm for creativity, cultivate academic spirit, improve humanistic qualities, develop healthy culture, promote campus cultural construction, and open up broader space for the development of the quality of postgraduates majoring in physical education. And through a series of academic exchange activities, it provides a positive atmosphere for the study and research of postgraduates and guides them to establish correct academic moral values.

\section{Conclusion}

In short, academic moral education reflects the characteristics of postgraduate moral education. From the perspective of college moral education, the moral education of postgraduate in sports subjects should have its own goals and requirements. Postgraduate have formed a basic world outlook and values, but most people do not have a work experience and their professional ethics are not yet mature. Therefore, academic moral education isn't only a requirement for postgraduate in physical education to study in school, but also a need for them to move forward to work independently and carry out research activities.

\section{REFERENCES}

[1] Li Shihong. Training Characteristics and Enlightenment of Postgraduate in Sports of University of St. Jonas Tadeu, Brazil[J]. Journal of Sports Culture, 2016, 23(12): 159-163.

[2] Wang Lijie, Chen Jiaqi. A Review of the 30-year Development Course of Graduate Education in Physical Education in Nanjing Normal University [J]. Journal of Sports Culture, 2016, 14(07): 136-142.

[3] Han Huijun, Xiao Jun. A Study on the Reform of the Cultivation Model of Postgraduate Majoring in Sports Based on Social Demands_-Based on the Investigation and Analysis of Four Independent Sports Colleges with Independent System[J]. Journal of Guangzhou Institute of Physical Education, 2015, 12(06):14 -16.

[4] He Yanhui. Reasons for the Anomalous Roles of Physical Education Postgraduate and Exploration of the True Regression [J]. Education and Occupation, 2013, 21(03):189-190.

[5] Zhao Zijian. Dynamic Optimization of Training Program for Postgraduates Majoring in Physical Education and Training [J]. Journal of Wuhan Institute of Physical Education, 2013, 18(04):78-84.

[6] Jin Jinshui, Zhu Zhengyu. Research on the Competitiveness of Graduate Education in Sports in Guangdong Province [J]. Journal of Guangzhou Institute of Physical Education, 2013, 12(01):7-10. 